\title{
Study on Curing Kinetics and Curing Mechanism of Epoxy Resin Based on Diglycidyl Ether of Bisphenol A and Melamine Phosphate
}

\author{
Wen-Yi Chen, ${ }^{1}$ Yez-Zen Wang, ${ }^{2}$ Feng-Chih Chang ${ }^{1}$ \\ ${ }^{1}$ Institute of Applied Chemistry, National Chiao Tung University, Hsinchu, Taiwan \\ ${ }^{2}$ Department of Chemical Engineering, National Yun-Lin University of Science and Technology, Yun-Lin, Taiwan
}

Received 22 February 2003; accepted 11 November 2003

\begin{abstract}
The curing kinetics of the diglycidyl ether of bisphenol A/melamine phosphate (DGEBA/MP) was analyzed by the DSC technique. The Kissinger and Flynn-WallOzawa methods were applied to determine the dynamic kinetics of the DGEBA/MP system. The activation energies obtained by these two methods were 83.9 and $85.6 \mathrm{~kJ} / \mathrm{mol}$, respectively. An autocatalytic equation was applied to determine the isothermal curing kinetics of the DGEBA/MP system. The DGEBA/MP system exhibits autocatalytic behavior in the isothermal curing procedure, whose kinetics fits well with the autocatalytic mechanism. The obtained
\end{abstract}

isothermal curing activation energy of the DGEBA/MP system was $110.0 \mathrm{~kJ} / \mathrm{mol}$. The curing mechanism of DGEBA with melamine phosphate was investigated using FTIR, ${ }^{13} \mathrm{C}$ solid-state NMR, and ${ }^{31} \mathrm{P}$ solid-state NMR. It involved an epoxide-amine reaction, etherification of phosphoric acid and epoxy, dehydration, and thermal oxidation of the hydroxyl group of the DGEBA/MP system. () 2004 Wiley Periodicals, Inc. J Appl Polym Sci 92: 892-900, 2004

Key words: epoxy resin; melamine phosphate; kinetics (polym.); FTIR; activation energy

\section{INTRODUCTION}

Epoxy resins have been widely used in coatings, adhesives, insulating materials, and composites because of their great versatility, low shrinkage, good chemical resistance, adhesion, and high-grade electrical insulation. Like most organic polymeric materials, the flammability of epoxy resins is rather high, thus limiting their applications in certain areas. Therefore, melamine phosphate is introduced herein as a curing agent and a flame retardant to improve the flame retardation of epoxy resins.

An optimal curing process depends on understanding the curing kinetics, the curing mechanism, and accurate modeling of the curing process. This modeling includes determination of the mechanism, or appropriate kinetic equation for the analyzed system, measurement of the reaction orders, and activation energies of the reaction. An accurate model not only helps to predict curing behavior for process design and control, but also can be used to predict aging and degradation of thermosetting polymer systems. It can further be used to compare the curing behavior of different systems or formulations using different matrices, catalysts, fillers, and additives.

The current understanding of the mechanism and kinetics of curing lags the rapid increase in formula-

Correspondence to: F.-C. Chang (Changfc@mail.nctu.edu.tw).

Journal of Applied Polymer Science, Vol. 92, 892-900 (2004)

(C) 2004 Wiley Periodicals, Inc. tions and the industrial applications of epoxy-based resins and composite systems. The mechanism and kinetics of curing are not yet comprehensively understood, and an accurate model of an optimal curing process has yet to be clearly established. ${ }^{1}$ To date, no study has been reported on modeling the curing of the diglycidyl ether of bisphenol $\mathrm{A} /$ melamine phosphate (DGEBA/MP) system.

An appropriate method must be used to measure, accurately, the cure kinetics parameters: the degree of conversion $(\alpha)$, conversion rate $(d \alpha / d t)$, and the activation energy $(E)$.

The rate of conversion can therefore be defined as follows:

$$
\frac{d \alpha}{d t}=\frac{d H / d t}{\Delta H_{\mathrm{Rxn}}}
$$

where $\Delta H_{\mathrm{Rxn}}$ is the heat of reaction. DSC techniques use two basic approaches: isothermal curing is carried out at a single cure temperature and at a given cure cycle, and dynamic curing is carried out at a constant heating rate.

\section{Dynamic kinetics}

Kinetic analyses were performed using two kinetic models, the Kissinger and the Flynn-Wall-Ozawa ${ }^{4-6}$ models. These two methods were used in this study, instead of other nonisothermal methods, because they 


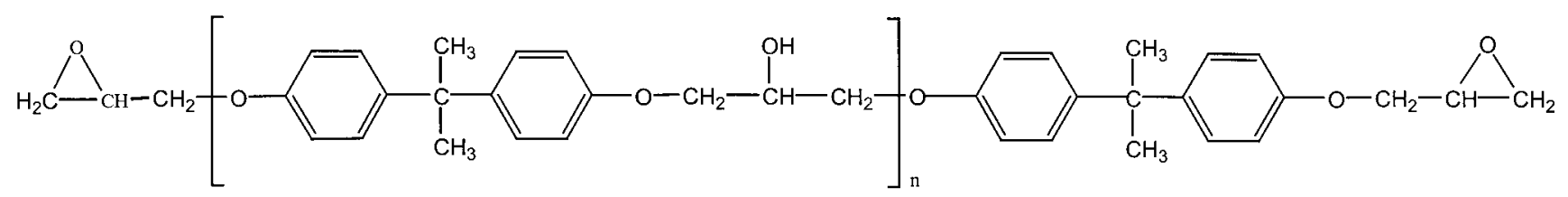

(a) DGEBA<smiles>Nc1nc(N)nc(N[C@H](O)P(=O)(O)O)n1</smiles>

(b) Melamine Phosphate

Figure 1 Chemical structures of this study.

do not require prior knowledge of the reaction mechanism to quantify kinetic parameters.

According to the method of Kissinger, the activation energy can be obtained from the maximum reaction rate, where $d(d \alpha / d t) / d t$ is zero at a constant-heating rate condition. The resulting relation can be expressed as

$$
\frac{d\left[\ln \left(q / T_{m}^{2}\right)\right]}{d\left(1 / T_{m}\right)}=-\frac{E}{R}
$$

where $T_{m}$ is the temperature at which the rate is maximum and $q$ is a constant heating rate. Therefore, a plot of $\ln \left(q / T_{m}^{2}\right)$ versus $1 / T_{m}$ gives the activation energy without the need to make any assumption about the conversion-dependent function.

Based on Doyle's approximation, ${ }^{7}$ Flynn-WallOzawa developed an alternative method to calculate the activation energy:

$$
\log (q)=\log \left[\frac{A E}{g(\alpha) R}\right]-2.315-\frac{0.457 E}{R T}
$$

Based on this equation, a more accurate value of the activation energy can be obtained by iteration or a least-squares technique to improve the linear approximation of the temperature integration term.

\section{Isothermal kinetics}

The conversion and the rate of conversion vary continuously throughout the process of reaction as the uncured resin is isothermally cured. Using DSC the conversion is measured as

$$
\alpha_{t}=\frac{\Delta H_{h}}{\Delta H_{\mathrm{Rxn}}}
$$

where the subscript $t$ indicates the value at time $t$ and $\Delta H_{h}$ is the heat of reaction at time $t$. An alternative method is to measure the heat evolved during the crosslinking of the partially cured sample. This latter method becomes necessary when the exothermic energy is too small to be detected by the former method. A distinct advantage of the latter method is that it allows $T_{g}$ and the conversion to be measured simultaneously. ${ }^{8,9}$ Using this method, the percentage of conversion is calculated as

$$
\alpha_{t}=\frac{\Delta H_{\mathrm{Rxn}}-\Delta H_{r}}{\Delta H_{\mathrm{Rxn}}}
$$

where $\Delta H_{r}$ is residual heat of reaction. The analysis of autocatalyzed curing reactions assumes, in contrast, that at least one of the reaction products is also involved in the propagation reaction characterized by an accelerating isothermal conversion rate. The kinetics of autocatalyzed reactions is described as follows ${ }^{8}$ :

$$
\frac{d \alpha}{d t}=k^{\prime} \alpha^{m}(1-\alpha)^{n}
$$

where $m$ and $n$ are the reaction orders and $k^{\prime}(T)$ is the specific rate constant. 


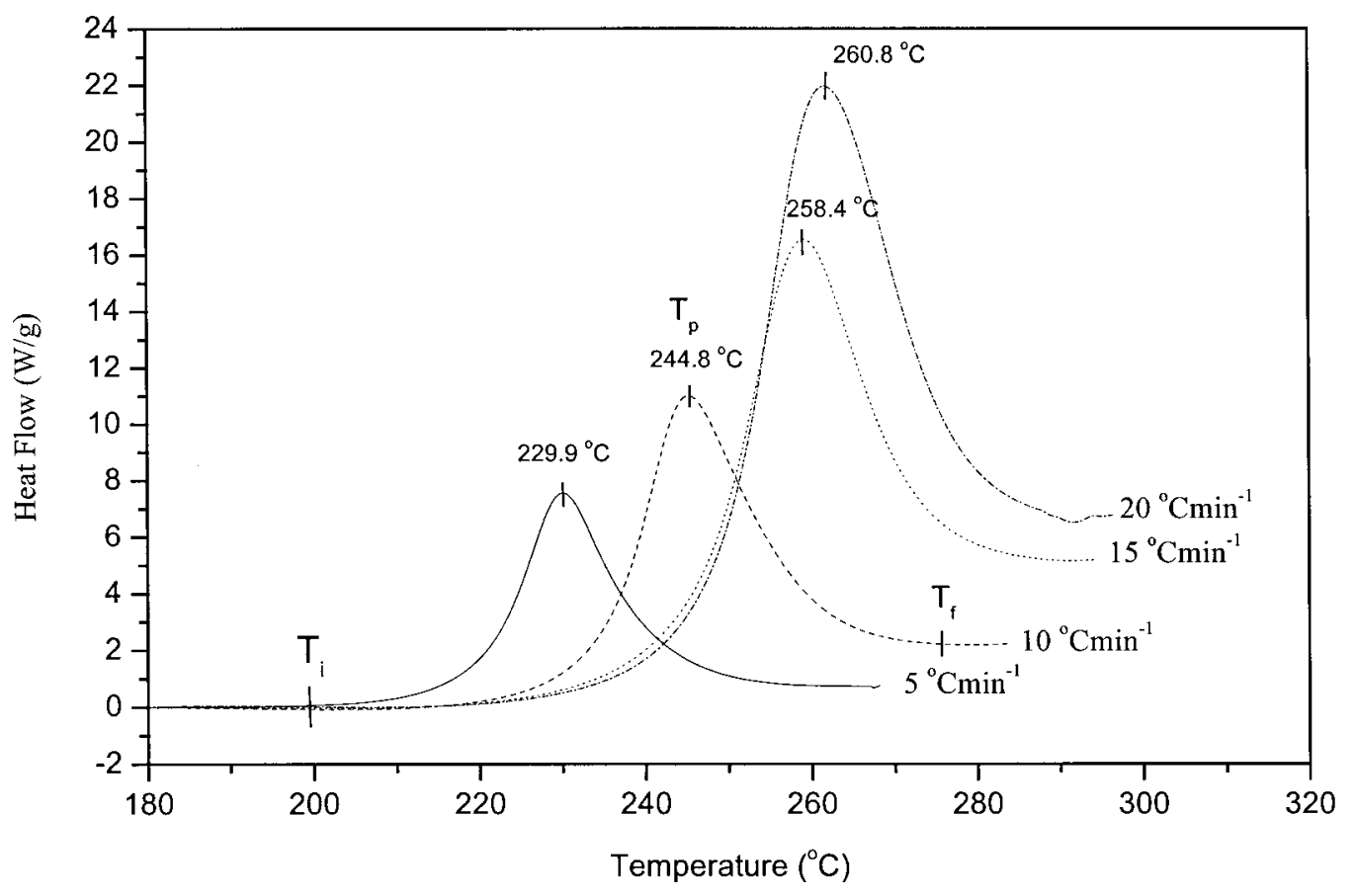

Figure 2 Typical dynamic DSC thermogram of DGEBA/MP.

The curing of the epoxy resin, with amino curing agents, involves three principal reactions: epoxide-primary amine addition; epoxide-secondary amine reaction; and etherification of epoxide-hydroxyl, branching, and crosslinking, respectively. ${ }^{10-15}$ These chemical reactions cause a complicated change in the physical state, from a viscous liquid to a gel, and eventually vitrify the material. FTIR and NMR were used to characterize chemical reactions of the epoxy resin.

The kinetics and mechanism of curing DGEBA with melamine phosphate have not yet been reported. This study reports that the melamine phosphate is able to function as a hardener and a flame retardant of the epoxy resin.

\section{EXPERIMENTAL}

\section{Materials}

The liquid epoxy resin used in this study was a diglycidyl ether of bisphenol A (BE-188) from Chang Chun Chemical Plastics of Taiwan with an equivalent

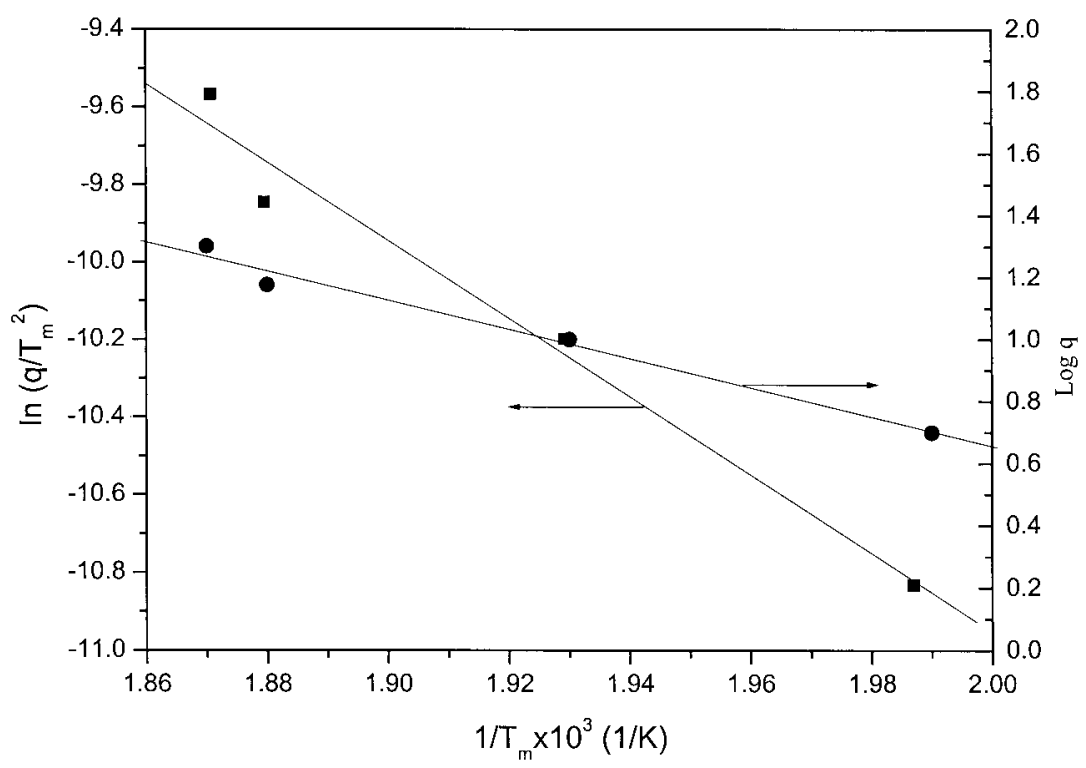

Figure 3 Activation energy of DGEBA/MP obtained by the Kissinger method and the Flynn-Wall-Ozawa method. 


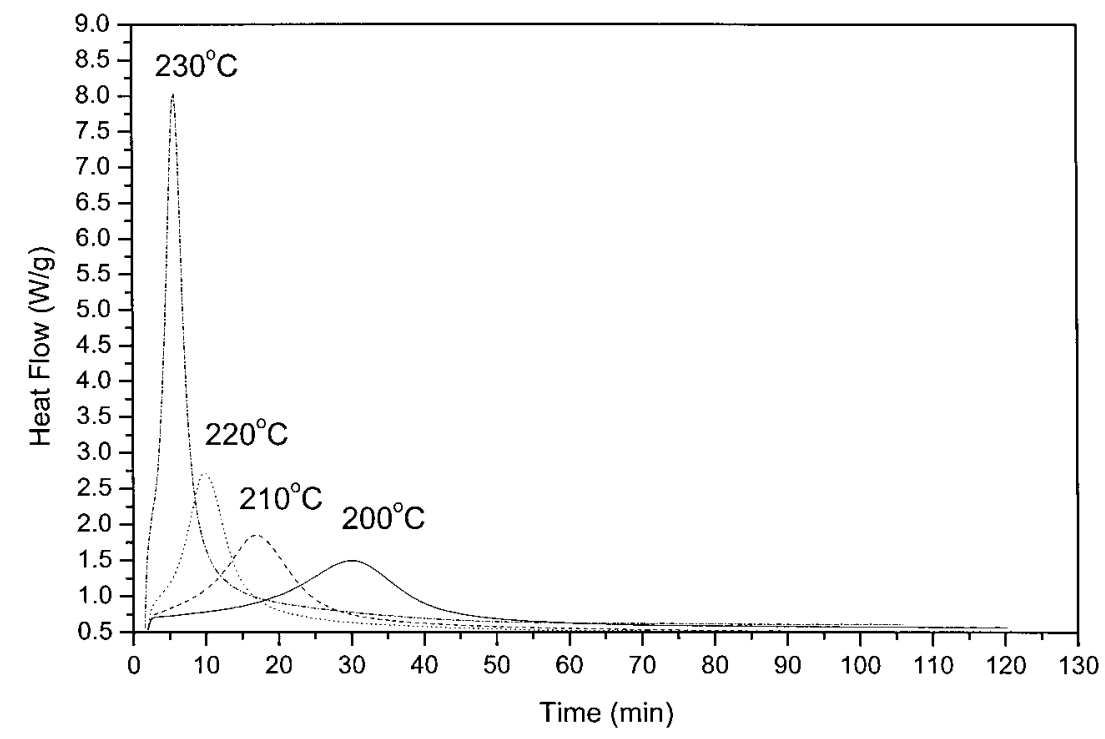

Figure 4 Typical isothermal DSC thermograms of DGEBA/MP at various curing temperatures.

epoxy molecular weight of $188 \mathrm{~g} /$ eq. The hardener used was melamine phosphate (MP, $\left.\mathrm{C}_{3} \mathrm{~N}_{6} \mathrm{H}_{3} \cdot \mathrm{H}_{3} \mathrm{PO}_{4}\right)$, also from Chung-Shan Institute of Science and Technology, Taiwan. Figure 1 presents the chemical structures of these compounds.

\section{Dynamic-curing kinetics}

A stoichiometric ratio of epoxy to amine was used in this DGEBA/MP system. The dynamic curing kinetics of the DGEBA/MP system was determined using a DuPont 2910 differential scanning calorimeter (DuPont, Boston, MA) operated in a nitrogen atmosphere. The sample weight of 6-7 mg was placed in a sealed aluminum sample pan. A dynamic curing reaction scan was conducted from 30 to $350^{\circ} \mathrm{C}$ at a heating rate of $5,10,15$, or $20^{\circ} \mathrm{C} / \mathrm{min}$ and a nitrogen flow rate of 40 $\mathrm{mL} / \mathrm{min}$.

\section{Isothermal-curing kinetics}

Isothermal curing was conducted at four different temperatures: $200,210,220$ and $230^{\circ} \mathrm{C}$.

\section{FTIR}

The sample was placed on a $\mathrm{KBr}$ pellet and FTIR spectrum was obtained at $220^{\circ} \mathrm{C}$ using a Nicolet Avatar 320 FTIR (Nicolet Analytical Instruments, Madi-

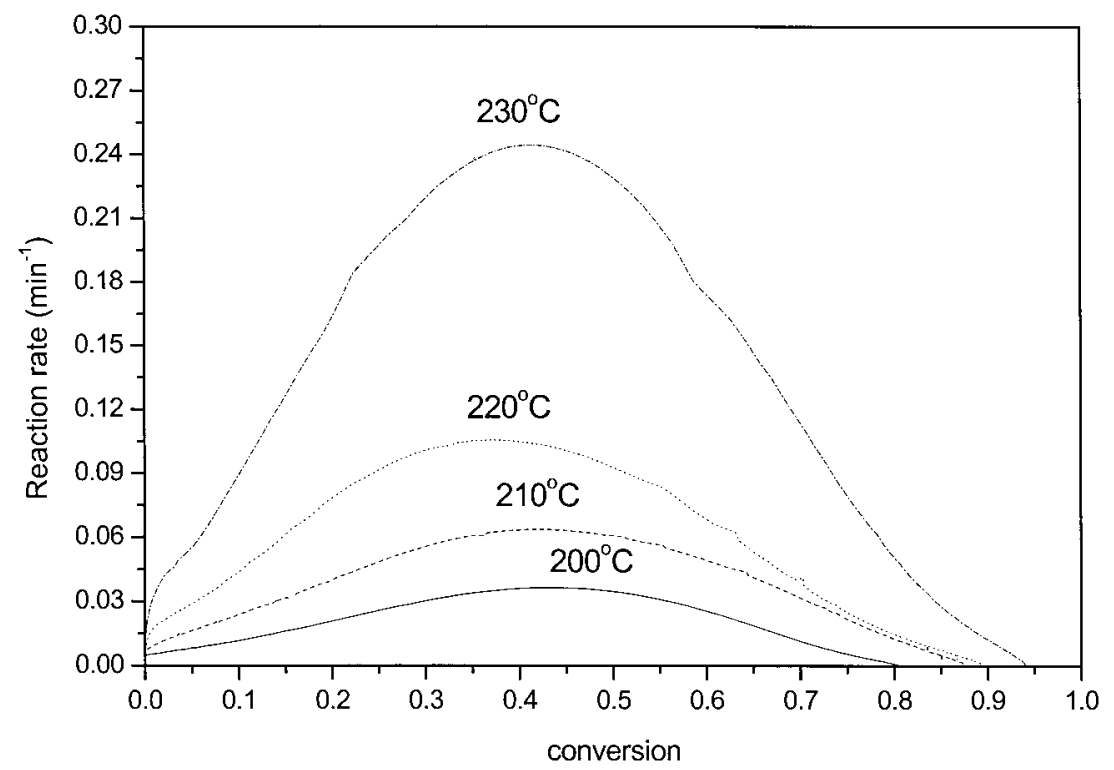

Figure 5 Reaction rate versus conversion of DGEBA/MP at various curing temperatures. 
TABLE I

Data of Isothermal Curing of DGEBA/MP for Various Curing Temperatures

\begin{tabular}{ccccc}
\hline $\begin{array}{c}\text { Curing } \\
\text { temperature }\left({ }^{\circ} \mathrm{C}\right)\end{array}$ & $\begin{array}{c}\text { Reaction rate } \\
\text { constant } \\
\left(K, \mathrm{~min}^{-1}\right)\end{array}$ & $m$ & $n$ & $m+n$ \\
\hline 200 & 0.13 & 0.97 & 0.87 & 1.84 \\
210 & 0.31 & 1.05 & 1.48 & 2.53 \\
220 & 0.84 & 1.19 & 1.99 & 3.18 \\
230 & 3.66 & 1.48 & 3.20 & 4.68 \\
$\begin{array}{c}\text { Average reaction } \\
\text { order }\end{array}$ & & 1.17 & 1.88 & 3.05 \\
Activation energy \\
$\left(E_{a} \mathrm{~kJ} \mathrm{~mol}^{-1}\right)$
\end{tabular}

son, WI), to analyze the epoxide content of the system at a resolution of $2 \mathrm{~cm}^{-1}$.

\section{Solid-state NMR}

High-resolution solid-state ${ }^{13} \mathrm{C}-\mathrm{NMR}$ and ${ }^{31} \mathrm{P}-\mathrm{NMR}$ experiments were carried out at room temperature using a Bruker DSX-400 spectrometer (Bruker Instruments, Billerica, MA) operated at resonance frequencies of 399.53-100.47 and 399.53-161.72 MHz for ${ }^{13} \mathrm{C}$ and ${ }^{31} \mathrm{P}$, respectively. The ${ }^{13} \mathrm{C}$ and ${ }^{31} \mathrm{P} \mathrm{CP} / \mathrm{MAS}$ spectra were measured with a 3.9- $\mu$ s $90^{\circ}$ pulse, with 3-s pulse delay time, acquisition time of $30 \mathrm{~ms}$, and 2048 scans. All NMR spectra were taken at $300 \mathrm{~K}$ using broadband proton decoupling and normal cross-polarization pulse sequencing. A magic angle sample spinning (MAS) rate of $5.4 \mathrm{kHz}$ was used to eliminate resonance broadening attributed to the anisotropy of the chemical shift tensors.

\section{RESULTS AND DISCUSSION}

\section{Dynamic kinetics}

Both Kissinger and Flynn-Wall-Ozawa methods assume that the DSC peak exotherm is isoconversion and its value is independent of the heating rate. These two methods were applied to the data obtained in the dynamic heating experiments at different heating rates between 5 and $20^{\circ} \mathrm{C} / \mathrm{min}$ used in this work. Figure 2 shows the heat flow measured by DSC cured under various heating rates. The temperature of maximum rate increases from 229.9 to $260.8^{\circ} \mathrm{C}$ with the increase of the heating rate.

By applying the Flynn-Wall-Ozawa and Kissinger methods of the maximum reaction rates (peaks of the DSC thermogram), activation energies can be determined by slopes of the lines shown in Figure 3. The obtained activation energies, based on the Kissinger and Flynn-Wall-Ozawa methods, are 83.9 and 85.6 $\mathrm{kJ} / \mathrm{mol}$, respectively. The activation energy, obtained by the Flynn-Wall-Ozawa method, is only slightly higher than that obtained by the Kissinger method, and the difference is insignificant. ${ }^{16}$

\section{Isothermal kinetics}

The kinetics of epoxy-amine reactions has been well established in the literature. ${ }^{17-21}$ In the DSC curve of dynamic curing for the DGEBA/MP system, at a heating rate of $10^{\circ} \mathrm{C} / \mathrm{min}$ as shown in Figure $2, T_{i}\left(199.2^{\circ} \mathrm{C}\right)$ is the initial temperature of the curing reaction, $T_{p}$ $\left(244.8^{\circ} \mathrm{C}\right)$ is the peak maximum temperature, and $T_{f}$ $\left(276.4^{\circ} \mathrm{C}\right)$ is the final temperature, respectively. Based on this result, this study used isothermal curing temperatures of $200,210,220$, and $230^{\circ} \mathrm{C}$.

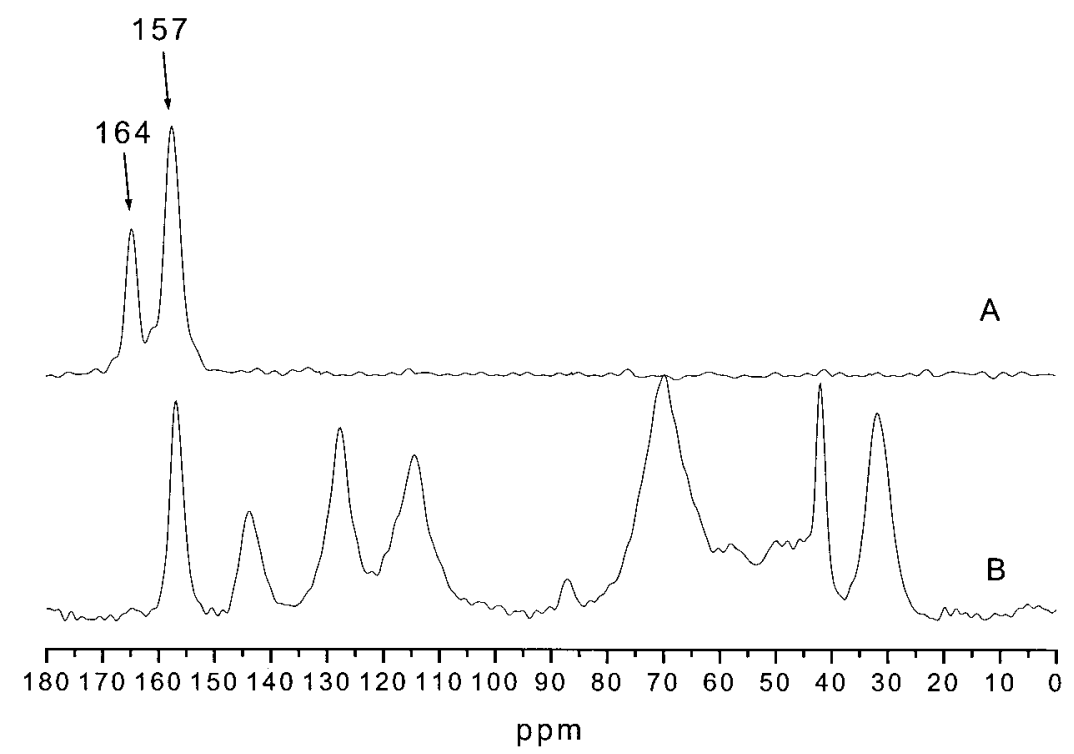

Figure $6{ }^{13} \mathrm{C}$ solid-state NMR of (A) melamine phosphate and (B) DGEBA cured with melamine phosphate. 
<smiles>CC1[C@H](CNc2nc(N)nc(N)n2)C1(C)OP(=O)(O)O</smiles>

Scheme 1 Decomposition of melamine phosphate.

Figure 4 shows the typical isothermal DSC thermograms of the DGEBA/MP system. The maximum times, for the reaction peaks at curing temperatures of 200, 210, 220, and $230^{\circ} \mathrm{C}$, are 29.8, 16.9, 9.9, and 5.7 $\mathrm{min}$, respectively. The reaction rate at any temperature increases with time and passes through a maximum. The maximum reaction peak becomes higher, and less time is needed, as the isothermal temperature is increased. Figure 5 plots the reaction rate versus conversion of the DGEBA/MP system. This result indicates that the curing reaction of the DGEBA/MP system is strongly autocatalytic in nature and thus eq. (6) is applicable. Table I shows kinetic parameters obtained for DGEBA cured with MP. The reaction orders $(n+$ $m$ ) of isothermal curing at $200,210,220$, and $230^{\circ} \mathrm{C}$ obtained from eq. (6) are 1.84, 2.53, 3.18, and 4.68, respectively. The $R^{2}$ coefficient of fitted data is 0.998 . Many previous studies have assumed that the overall reaction order is 2 for the epoxy-amine reaction of the epoxy/amine system, at a relatively lower curing temperature, and that etherification and homopolymerization reactions could be neglected. ${ }^{22-25}$ Other studies have also reported that the reaction order $(n+m)$ of the epoxy-amine reaction was near 2 under isothermal curing. ${ }^{26,27}$ In this study, the overall order of the curing reaction of the DGEBA/MP system at $200^{\circ} \mathrm{C}$ is 1.84. Therefore, the DGEBA/MP system undergoes an epoxy-amine reaction at low curing temperature.

Figure 2 shows that the initial curing temperature $\left(T_{i}\right)$ of the DGEBA/MP system was $199.2^{\circ} \mathrm{C}$. Therefore, it is similar to that of isothermal curing at $200^{\circ} \mathrm{C}$ for the DGEBA/MP system. At 210 and $220^{\circ} \mathrm{C}$, the overall curing reaction orders of the DGEBA/MP system are 2.53 and 3.18, respectively. The etherification of an epoxide ring and a hydroxyl group forms an ether linkage, which becomes significant at high curing temperature in certain epoxy resin/amine systems. The importance of this reaction, in terms of its effect on the network, was previously reported. ${ }^{28,29}$ Many studies have assumed that the overall reaction order was 3 for etherification of the epoxy/amine system at later stages of curing and at a high curing temperature. ${ }^{30-32}$ The literature indeed demonstrated that the reaction order of etherification is near $3 .{ }^{31}$ The obtained overall

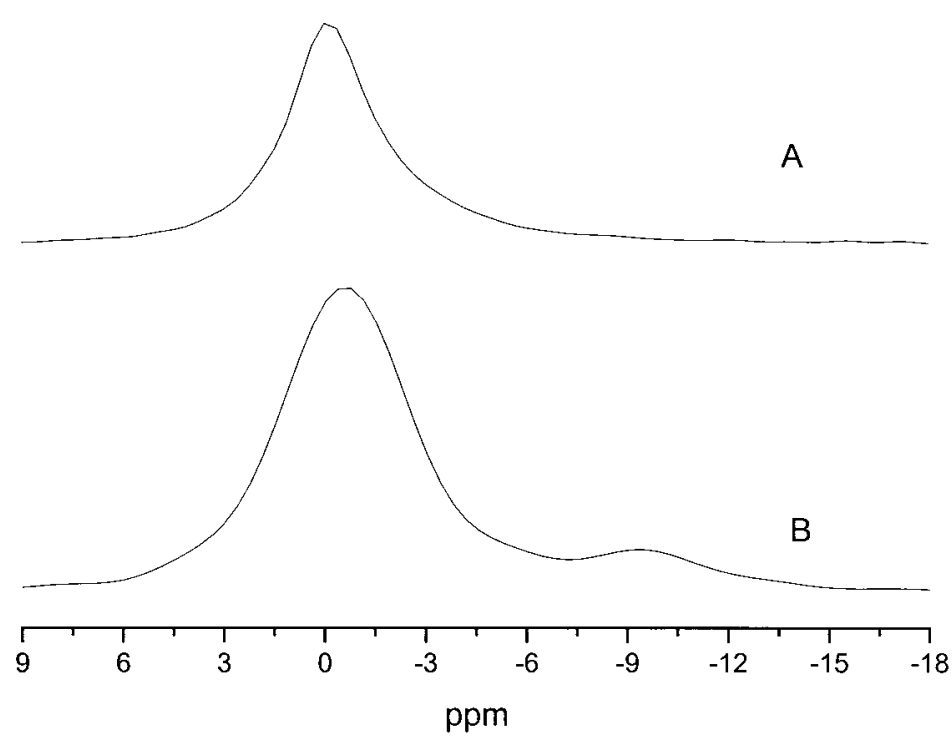

Figure $7{ }^{31} \mathrm{P}$ solid-state NMR of (A) melamine phosphate and (B) DGEBA cured with melamine phosphate. 


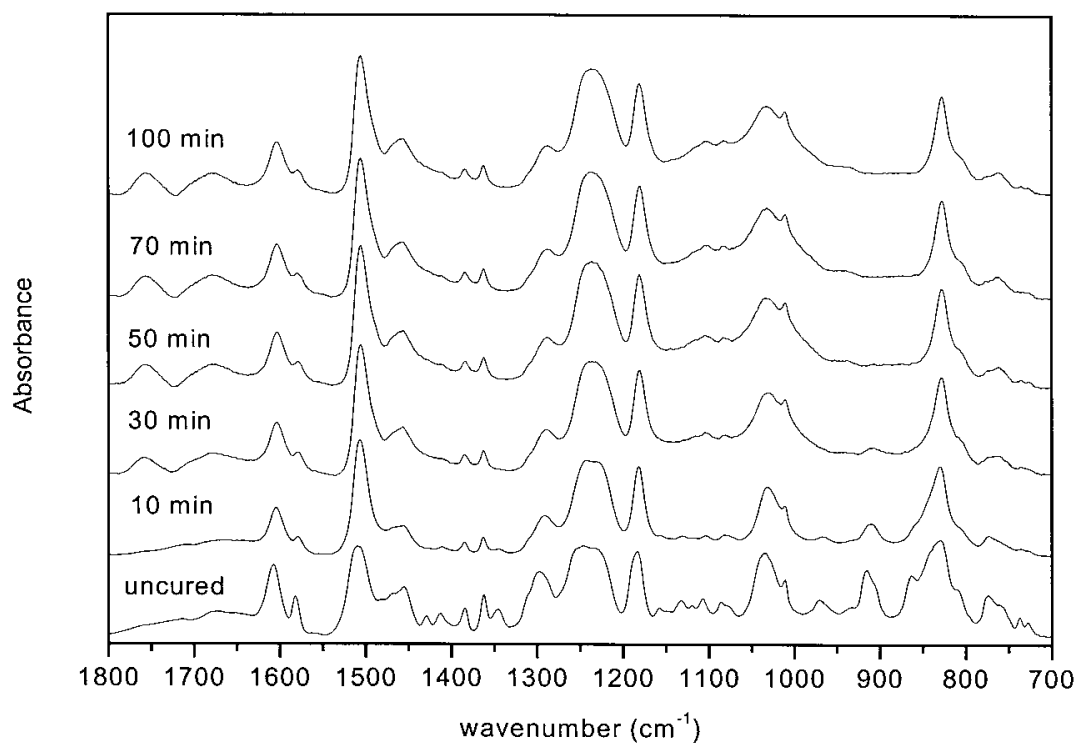

Figure 8 FTIR spectra, at various times, of DGEBA/MP at $220^{\circ} \mathrm{C}$.

curing reaction order of the DGEBA/MP system was 3.18 , close to 3 , at $220^{\circ} \mathrm{C}$. Therefore, at a high curing temperature of $220^{\circ} \mathrm{C}$, the DGEBA/MP system exhibited etherification between the epoxide ring and the hydroxyl group. At $230^{\circ} \mathrm{C}$, the overall curing reaction order of the DGEBA/MP system was 4.68.

The reaction rate constants at isothermal-cure temperatures of $200,210,220$, and $230^{\circ} \mathrm{C}$ were $0.13,0.31$, 0.84 , and $3.66 \mathrm{~min}^{-1}$, respectively. The reaction rate constant increased with increasing isothermal temper- ature and the activation energy of isothermal curing was $110.0 \mathrm{~kJ} / \mathrm{mol}$.

\section{Curing mechanism}

The curing mechanism of the epoxy/amine system was characterized by NMR and FTIR. Figure 6 shows the ${ }^{13} \mathrm{C}$ solid-state NMR spectrum of the melamine phosphate. The absorption peaks of the $-\mathrm{N}=\mathrm{C}-\mathrm{N}-$ group, and its hydrogen bonding with

Epoxide-amine reaction(1 $1^{0}$ amine)

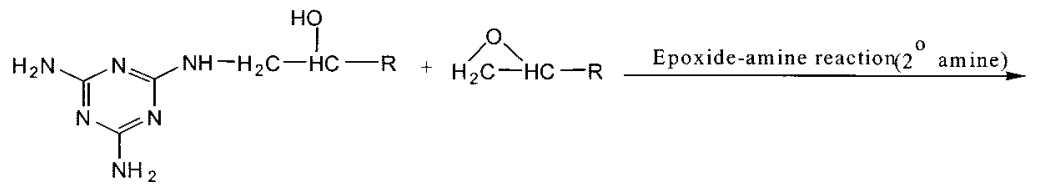

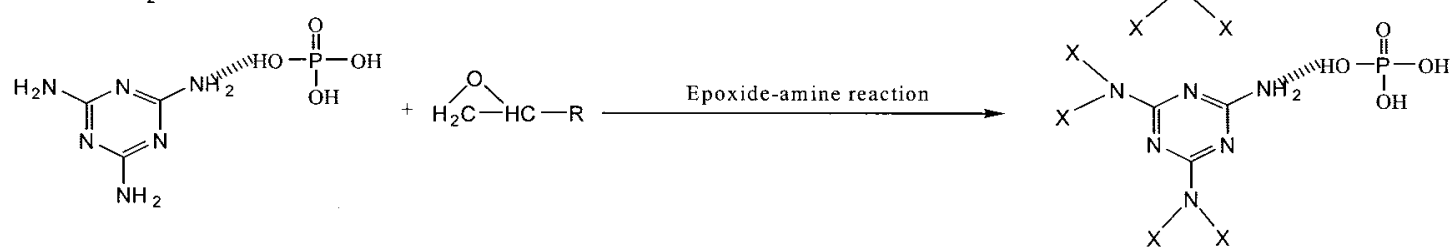
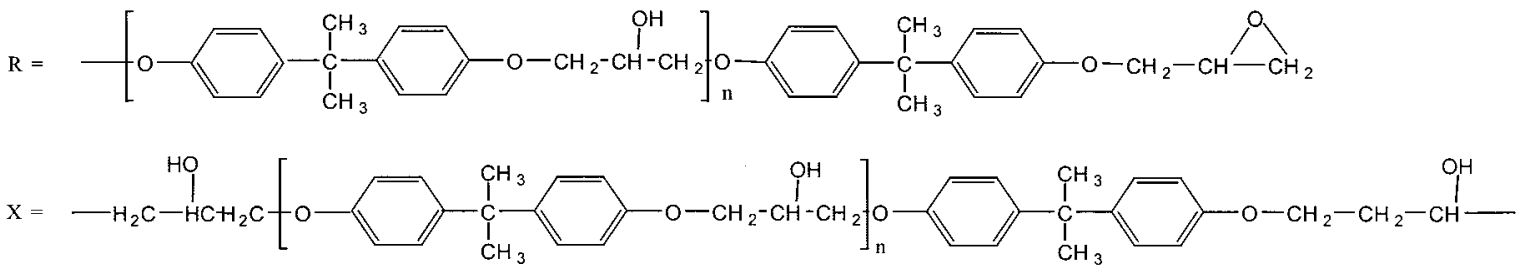

Scheme 2 Epoxide-amine reaction of DGEBA/MP and DGEBA/melamine. 


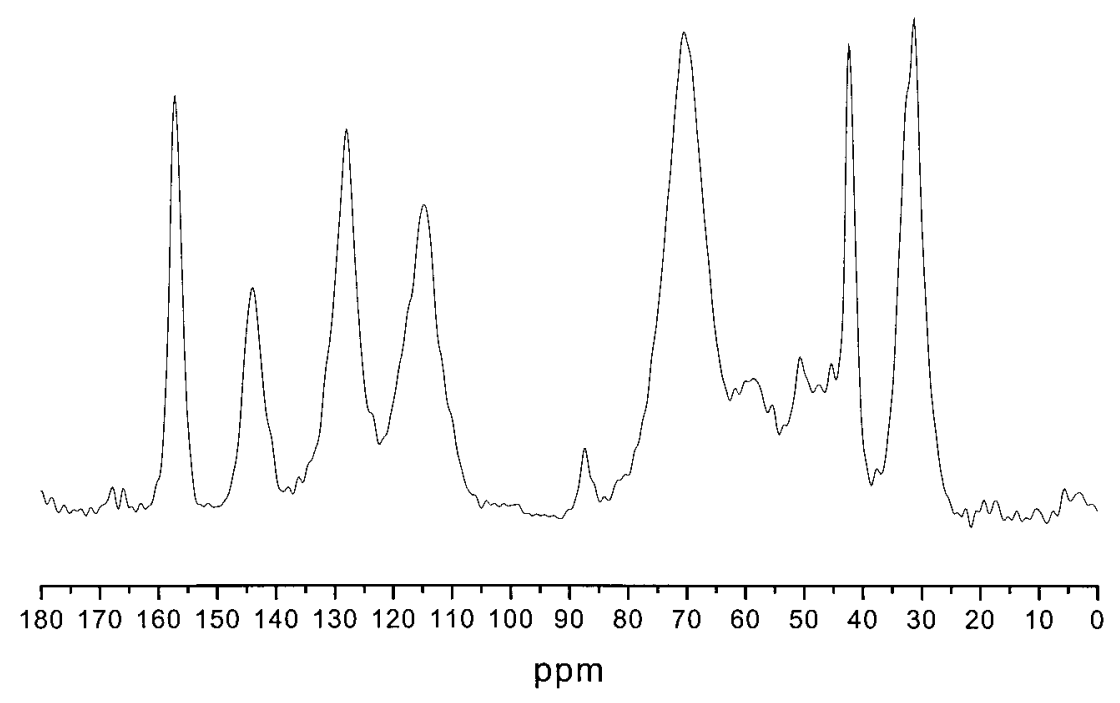

Figure $9{ }^{13} \mathrm{C}$ solid-state NMR of DGEBA cured with melamine.

hydroxyl, are at 157 and $164 \mathrm{ppm}$, respectively. Figure 6 shows the ${ }^{13} \mathrm{C}$ solid-state NMR spectrum of DGEBA cured with melamine phosphate, at $220^{\circ} \mathrm{C}$ for $100 \mathrm{~min}$, where the peak at $164 \mathrm{ppm}$ almost disappears, implying that most melamine phosphate is decomposed into melamine and phosphoric acid as shown in Scheme 1. Figure 7(A) shows the ${ }^{31} \mathrm{P}$ solid-state NMR spectrum of the melamine phosphate and the DGEBA cured with melamine phosphate where the absorption peak of phosphoric acid is at $0 \mathrm{ppm}$.

For the amine-epoxide reaction, Figure 8 shows the IR absorption spectra of the initial (uncured) and after heat treatments at $220^{\circ} \mathrm{C}$ for various time periods. A comparison of these spectra, for curing at $220^{\circ} \mathrm{C}$, reveals that the stretching vibration band of the epoxy ring at $915 \mathrm{~cm}^{-1}$ decreases and shifts downward. At the same time, the absorption peak of the $\mathrm{NH}_{2}$ group at $774 \mathrm{~cm}^{-1}$ also decreases. These results are related to the epoxide-amine reaction for the epoxy/amine system. Scheme 2 presents the mechanism of the epoxide-amine reaction. Figure 9 shows the ${ }^{13} \mathrm{C}$ solidstate NMR spectrum of DGEBA cured with melamine at $220^{\circ} \mathrm{C}$ for $100 \mathrm{~min}$, which is essentially the same as the DGEBA cured with melamine phosphate. Therefore, the epoxide-amine reaction of the DGEBA/MP system indeed occurs between melamine and the epoxy.

Figure 8 shows that the absorption peak of the $-\mathrm{P}-\mathrm{O}-\mathrm{C}$ - group at $1016 \mathrm{~cm}^{-1}$ increases with curing time, implying that the DGEBA/MP system undergoes etherification during curing. Figure $7(B)$ shows the ${ }^{31} \mathrm{P}$ solid-state NMR spectrum of DGBEA cured with melamine phosphate at $220^{\circ} \mathrm{C}$, with major and minor peaks at 0 and $-9 \mathrm{ppm}$, respectively. The major peak corresponds to the phosphoric content, whereas the minor peak is attributed to $\mathrm{P}(=\mathrm{O})(\mathrm{OC})$ groups. Scheme 3 shows the mechanism of the etherification of the DGEBA/MP system.

For dehydration and thermal oxidation, Figure 8 shows that the absorption peak, of the $-\mathrm{C}=\mathrm{C}$ - group at $1670 \mathrm{~cm}^{-1}$, increases with curing time because of dehydration of the DGEBA/MP system occurring during later stages of curing, ${ }^{33}$ as shown in Scheme 4. The absorption peak, at $1757 \mathrm{~cm}^{-1}$ as shown in Figure 8 , is the ketone group resulting from the thermal oxidation of the hydroxyl group in the DGEBA/MP system occurring in the later stages of curing, as shown in Scheme 5. The area of this ketone peak increases with curing time, as shown in Figure 8. The IR spectra are able to demonstrate that dehydration and thermal oxidation of the hydroxyl group of the DGEBA/MP<smiles>[X]OP(=O)(O[X])O[V]</smiles>

Scheme 3 Etherification of DGEBA $/ \mathrm{H}_{3} \mathrm{PO}_{4}$. 


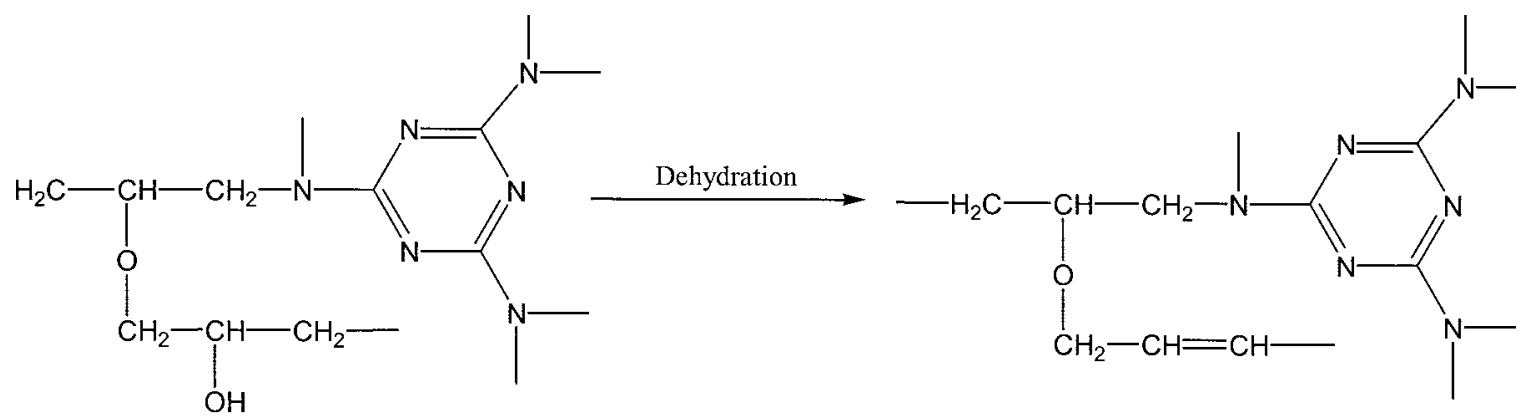

Scheme 4 Dehydration of DGEBA/MP.

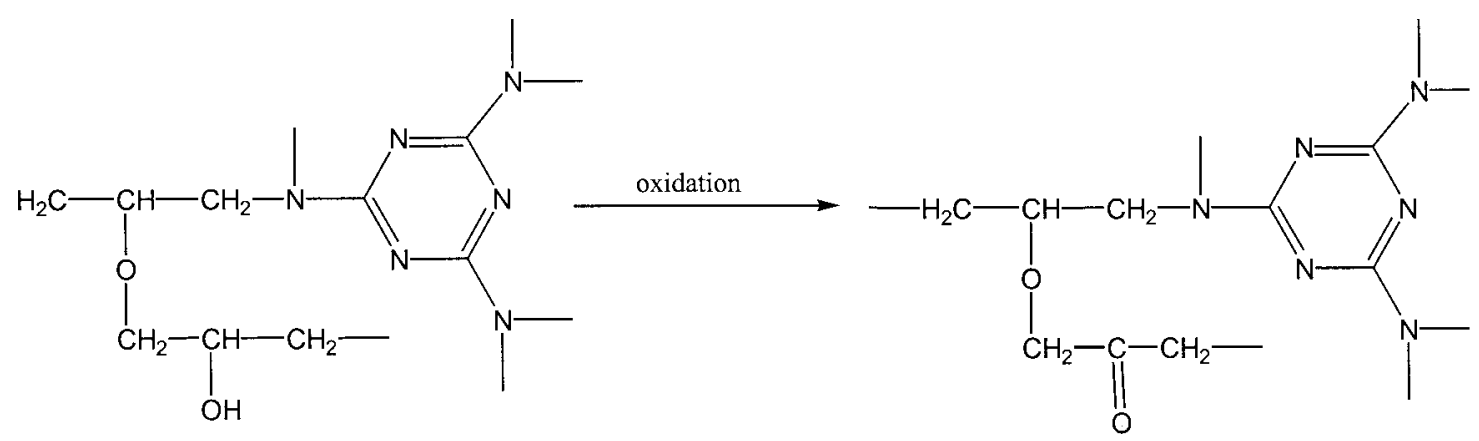

Scheme 5 Thermal oxidation of DGEBA/MP.

system occur simultaneously in the later stage of curing.

\section{CONCLUSIONS}

The Kissinger and Flynn-Wall-Ozawa methods were applied in defining dynamic kinetics of the DGEBA/MP system. The activation energies, obtained by these two methods, are 83.9 and $85.6 \mathrm{~kJ} / \mathrm{mol}$, respectively. For isothermal-curing kinetics, the DGEBA/MP system has an autocatalytic behavior and the isothermal-cure activation energy is $110.0 \mathrm{~kJ} / \mathrm{mol}$. The curing mechanism of the DGEBA/MP system involves the epoxide-amine reaction, etherification of phosphoric between phosphoric acid and epoxy, dehydration, and thermal oxidation of the hydroxyl group of the DGEBA/MP system.

\section{References}

1. Boey, F. Y. C.; Qiang, W. Polymer 2000, 412081.

2. Richardson, M. J. Pure Appl Chem 1992, 64, 1789.

3. Richardson, M. J. In: Clorimetry and Thermal Analysis of Polymers; Matho, V. B. F., Ed.; Hanser: New York, 1993; p. 91.

4. Kissinger, H. E. Anal Chem 1957, 29, 1702.

5. Flynn, J. H.; Wall, L. A. J Res Natl Bur Stand Part A Phys Chem 1996, 70A, 487.

6. Ozawa, T. Bull Chem Soc Jpn 1965, 38, 1881.

7. Nam, J.; Seferis, J. C. J Appl Polym Sci 1993, 50, 1555.

8. Farris, R. J.; Lee, C. Polym Eng Sci 1983, 23, 586.

9. Fava, R. A. Polymer 1968, 9, 137.

10. Kamal, M. R. Polym Eng Sci 1974, 14, 23.
11. Dusek, L. Adv Polym Sci 1986, 1, 78.

12. Wang, X.; Gillham, J. K. J Appl Polym Sci 1991, 43, 2267.

13. Kreibich, U. T.; Schmid, R. J Polym Sci Part C 1975, 53, 177.

14. Dusek, K.; Plestil, J.; Lednicky, F. Polymer 1978, 19, 393.

15. Keenan, J. D.; Seferis, J. C. J Appl Polym Sci 1979, 24, 2375.

16. Munns, T. E.; Seferis, J. C. J Appl Polym Sci 1983, 28, 2227.

17. Serier, A.; Pascault, J. P.; L. T. My, J Polym Sci Part A: Polym Chem 1991, 29, 209.

18. Li, Y. S.; Li, M. S.; Chang, F. C. J Polym Sci Part A: Polym Chem 1999, 37, 3614.

19. Barral, L.; Cano, J.; Lopez, J.; Lopez-Bueno, I.; Nogueira, P.; Abad, M. J.; Ramirez, C. J Polym Sci Part B: Polym Phys 2000, 38, 351.

20. Lin, Y. G.; Sautereau, H.; Pascault, J. P. J Polym Sci Part A: Polym Chem 1986, 24, 2171.

21. Barral, L.; Cano, J.; Lopez, J.; Lopez-Bueno, I.; Nogueira, P.; Abad, M. J.; Ramirez, C. Polymer 2000, 41, 2657.

22. Mijovic, J.; Kim, J. H.; Slaby, J. J Appl Polym Sci 1984, 29, 1449.

23. Moroni, A.; Mijovic, J.; Pearce, E.; Foun, C. C. J Appl Polym Sci 1986, 32, 3761.

24. Mijovic, J.; Wang, H. T. J Appl Polym Sci 1989, 37, 2661.

25. Ryan, M. E.; Dutta, A. Polymer 1979, 20, 203.

26. Khanna, U.; Chanda, M. J Appl Polym Sci 1993, 49, 319.

27. Stefani, P. M.; Moschiar, S. M.; Aranguren, M. I. J Appl Polym Sci 2001, 79, 1771.

28. Bokare, U. M.; Ghandi, S. K. J Polym Sci Part A: Polym Chem 1980, 18, 857.

29. Duesk, K. Polym Bull 1985, 13, 321.

30. Xu, L. S.; Schlup, J. R. J Appl Polym Sci 1998, 67, 895.

31. Liu, Y. F.; Zhao, M.; Shen, S. G.; Gao, J. G. J Appl Polym Sci 1998, 70, 1991.

32. Bonnaus, L.; Pascault, J. P.; Sautereau, H. Eur Polym Mater 2000, 36, 1313.

33. Kim, B. S.; Inoue, T. Polymer 1995, 36, 1985. 